\title{
Generation adequacy of electric power systems in market price setting
}

\author{
Natalia Aizenberg, Sergey Perzhabinsky* \\ Melentiev Energy Systems Institute of SB RAS Irkutsk, Russia
}

\begin{abstract}
We propose the new model of generation adequacy optimization. Optimization criterion is a maximum of social welfare. Social welfare consists of profits of generating companies, consumer surplus, costs for development and servicing of electrical grids. In the article we present a review of existed methods of adequacy level management in liberalized electric power systems. Optimization of adequacy level is based on analysis of variants of development of the electric power system. For adequacy analysis of the variants of development we multiple estimate the electricity shortage in random hours of the system work. Analysis of the system work in every random hour is realized in two stages. At first we define values of equilibrium electricity demand in every system node and equilibrium price of electricity according to Cournot model. We consider only electricity market in the model. At the next stage we simulate failures of power generating equipment and transmission lines. The electricity shortage in a current hour is estimated on the second stage. After a whole cycle of analysis, we compute reliability indexes and profits of generating companies. Profits of generating companies are depended on the reliability of the electricity supply. The simulations of random values are based on Monte Carlo method.
\end{abstract}

\section{Introduction}

Reliability of electricity supply can be defined as the ability of an electric power system to satisfy the demand for electricity with according to accepted standards and required volumes. Under that researchers distinguish the reliability of electricity regimes (security) and balance reliability (adequacy). Security is the ability of the electric power system to withstand sudden perturbations for continuity of electricity power supply. Adequacy is the ability of the system to provide consumer electricity and required power at any time. Achieving the required level of adequacy means creation enough reserves of electricity capacity, widening of transmitting capacity of power lines, providing of continuity of fuel supply for electric power stations.

Security acquires the form of public good and adequacy takes on the form of private good in liberalized electric power systems [1]. Payments for security and methods of its management have to be set centrally because security is the collective responsibility. Regulation of adequacy level can be carried out centrally (mainly in traditional electric power systems) and decentrally (in liberalized electric power systems). The given classification in general terms unites existed approaches to the management of the adequacy level. Every method of adequacy management defines specific mechanisms of price setting for the reliability of electricity supply, scales of new generating powers, ways of widening of transmitting capacity of a power network, choice of technology of electricity generation.
The technology of electricity generation determines the costs of its production and characterizes the stability of generators to fluctuations of fuel supply. In the regulation of reliability level of electricity supply researchers [2 - 4] distinguish short-run and long-run period. At the same time, researchers $[3,4]$ share one view that control of reliability level exacts centralized management in the short-run. One the mechanism of realization of such management is the establishment penalties to the system operator or regulator for electricity supply failures [4]. There is no one opinion in the literature about supporting requires adequacy level in the long-run.

The electricity markets are complexly organized, in particular, caused by the specificity of electricity as a product. The wholesale of electricity is carried out on the spot market. The spot market is a day ahead market. Generating companies and consumers give proposals of purchase or sale on the next day. The operator defines prices and volumes of sales and purchases on a base of the balance of demand and supply. The market participants can't change these defined volumes. In the current day balancing market acts on which deviations from the spot volumes are traded. Moreover, the capacity market can be the part of the electricity market. Generating capacities participated in the wholesale trade are determined on the capacity market. Trading of capacity holds with some periodicity, for example, once a year or half year. Another part of the electricity market is the retail market on which the big retailers interact with the small consumers. The trade on this market is

sergperj@gmail.com 
based on tariffs taking into account prices of above-listed markets. There are different mechanisms for trade regulation, which influence on reliability level of electricity supply.

The spot electricity markets can ensure high reliability level in short-run and long-run prospects. For the achievement of these results, we need the performance of the strong assumptions such as neutrality to risks, the convexity of technologies and others [5]. One of the biggest spot electricity markets in the world (Nord Pool Exchange) is an example of market management of the reliability level of electricity supply. The high prices on the market and electricity shortage in the short-run period stimulate to invest in the building of new generating capacities which increases the adequacy level in the long-run period. The low electricity prices and superfluous capacities lead to the exit of not efficient agents from the market $[3,5]$. There are some negative moments that arise under such reliability management. If the decisions of investment in new capacities are inopportunely made, we will see the growth of shortage states of electric power system. The similar situations were on spot markets of Australia and Great Britain [6].

Another way for management of reliability of electricity supply in liberalized electric power systems is the establishment of payments to generating companies for their capacity. There are two commodities, electric and capacity. At the same time, it is important if generating companies have additional capacities for supplying in peak loads. Capacity payments are formed on the base of reliability indexes (for example, LOLP) or segmentation of consumers by the character of their load. These policies can be realized through the setting of a tariff menu for electricity depending on different reliability of electricity supply with compensation of the value of lost load (VOLL). The given payments are incentives to invest in additional generating capacities (electricity market in Argentina and Spain).

Forward contracts on electricity and capacity are alternative of the direct capacity payments for stimulation of investments in the new generating capacities [7, 8]. In this case, producers diversify investment risks by forward contracts of electricity supply. Forward contract connects the capacity payments with an obligation to supply electricity with agreed prices. If the obligation doesn't realize, then the generating company will have to compensate the value of lost load. Electricity producers without the forward contracts have the right to sell electricity by prices of the free market which can be amounted to VOLL. Generating capacities will build if the cost of the required capacity by a contract exceed cost of the new generating capacity. Consumers can abandon new contracts and reduce their load in high price periods that lead to increase general reliability level of electricity supply [8]. This kind of reliability management was chosen in Great Britain after market failures at the end of the 90th [9].

Recently general electric policy strongly politicizes. As a result, active generating companies are disorientated. They can't take into account only commercial risks and have to consider possible political changes concerned with state interrelations and their electric policy. Risk hedging on a base of forward contracts is the main instrument for reliability decisions in this case.

The simplest way for reliability management is the establishment of requirements by the system operator to indispensable capacity reserves. Examples of such regulation are electricity markets in New York, New England, Russia [6]. Power capacity market allows to trade power reserves and effective adapt to requirements of power reservation. But as in the case of the capacity payments common effectiveness of such way of reliability management decreases under not optimally requirements of power reservation. Not effective requirements lead to the strengthening of monopoly power on the market or building of excess power reserves.

\section{Analysis and optimization of generation adequacy}

In the article, we present an approach to optimization of the adequacy of an electric power system based on the electricity spot market. We don't consider the capacity market and forward contracts market as tools for regulating generation adequacy. All indicators of market efficiency are formed on the basis of electricity market prices and possible costs of the electricity shortage.

Adequacy analysis of the electric power system is realized in the follow algorithm [10]. First of all, set of random hours of system work is formed. After that the electricity shortage is estimated for all random hours of system work. Finally, reliability indexes are computed.

We have to modify the given approach for adequacy optimization in liberalized electric power systems. For that we assume that every hour of electric power system work is characterized by a set of random node functions of electricity demand in the system. We suppose also a low elasticity of electricity demand. It is defensible because we discuss a long-term period of developing of the electric power system. Consequently, we can present a demand function as a linear.

Generating companies maximize profit taking into account total electricity demand and their generating capacities. We suppose to use Cournot model for simulation of described interaction on the electricity market [11] for every hour. A price and quantity of electricity are found as a result of searching of the equilibrium on the electricity market [12].

Further, we simulate failures of generating and network equipment which determine the quantity of generated electricity and capacity of network lines in every random hour. Working generating capacities and real capacity of transmission power lines define value of met electricity demand in the considered hour. Difference between equilibrium and computed values of electricity demand determines penalties of unreliable electricity supply for generating companies. This difference we will call electricity shortage. After adequacy analysis, we compute the reliability indexes such as the probability of electricity shortage, the 
mathematical expectation of electricity shortage and the mathematical expectation of electricity price.

Optimization of generation adequacy is realized on a base of adequacy analyzing of variants of development of electric power system. A variant of system development with the highest level of social welfare is optimal. Social welfare is a sum of profits of generating companies and consumer surpluses. We suppose that the government is a social planner which takes himself of network exploitation costs, but the costs of building of the electric power lines are paid by the generating companies.

\section{Price setting in the model}

The scheme of electric power system consists $n$ nodes and some set of system links. Let $N$ is a given number of simulated hours.

The inverse function of electricity demand is

$$
p_{i}^{k}=\beta_{i}^{k}-\alpha_{i} y_{i}^{k}
$$

for $k$-th hour, $k=1, \ldots, N$, in node $i, i=1, \ldots, n$. Here $y_{i}^{k}$ is quantity of consumed electricity in a node $i$ for $k$-th hour, $\mathrm{kWh}, p_{i}^{k}$ is electricity price in $i$-th node for one $\mathrm{kWh}, \alpha_{i}$ is a positive coefficient of $i$-th demand function, $\beta_{i}^{k}$ is meaning of random value $\beta_{i}$ with given distribution law, for example, truncated normal law for the interval $\left[\underline{\beta}_{i} ; \bar{\beta}_{i}\right], i=1, \ldots, n, k=1, \ldots, N$.

We suppose that equilibrium price is equal for all system nodes $\quad p_{i}\left(y^{k}\right)=p_{j}\left(y^{k}\right)=p\left(y^{k}\right) \quad$ for all $i \neq j$, $i=1, \ldots, n, j=1, \ldots, n$, where $y^{k}$ is the total amount of consumed electricity for $k$-th hour

$$
y^{k}=\sum_{i=1}^{n} y_{i}^{k}, k=1, \ldots, N
$$

Denote $p^{k}=p\left(y^{k}\right)$. We assume that $S$ is a number of generating companies with generating capacities located in different nodes. Generating company $s$ produces $x_{s i}^{k} \mathrm{kWh}$ electricity in $i$-th node. Total amount of electricity produced by $s$-th company is

$$
x_{s}^{k}=\sum_{i=1}^{n} x_{s i}^{k} \quad s=1, \ldots, S, k=1, \ldots, N
$$

Summary installed generating capacity of company $s$ in node $i$ is designated by $\bar{x}_{s i}$. The costs function for $s$ th generating company depends on the value of generated electricity $C_{s}\left(x_{s}^{k}\right), \quad s=1, \ldots, S$. Profit function of generating company $s$ is written as

$$
\pi_{s}\left(x_{s}^{k}, y^{k}\right)=p\left(y^{k}\right) x_{s}^{k}-C_{s}\left(x_{s}^{k}\right)
$$

For searching of equilibrium of Cournot-Nash it is necessary to maximize function (3) for every company $s$ in hour $k, k=1, \ldots, N$, subject to

$$
\begin{gathered}
\sum_{i=1}^{n} y_{i}^{k}=\sum_{s=1}^{S} \sum_{i=1}^{n} x_{s i}^{k} \\
0 \leq x_{s i}^{k} \leq \bar{x}_{s i}, i=1, \ldots, n .
\end{gathered}
$$

A standard method for solving the problem (3) - (5) is Cournot tatonnement method [13]. The main idea of the method consists of sequential maximization of profit function of $s$-th company with fixed values of generated electricity by other companies. Computational process converges if demand functions are linear and cost functions are quadratic.

An equilibrium in the model (3) - (5) in a $k$-th hour, $k=1, \ldots, N$, we denote by means of $\tilde{x}_{s i}^{k}, \tilde{y}_{i}^{k}$, $s=1, \ldots, S, i=1, \ldots, n$. According to (2) it is defined $\tilde{y}^{k}$ then the equilibrium price $p\left(\tilde{y}^{k}\right)$ and the profits of generating companies $\pi_{s}\left(\tilde{x}_{s}^{k}, \tilde{y}^{k}\right)$ are computed, $s=1, \ldots, S, k=1, \ldots, N$.

We don't consider network constraints in problem (3) - (5) and the electric power system is considered as a one node on this stage of computations. Network constraints are taken into account on the second stage of developed approach under searching for electricity shortage in the electric power system.

\section{The model of electricity shortage estimation}

After finding equilibrium in the model (3) - (5) we have to simulate failures of generating and network equipment defining the maximal value of generated and transmitted electricity between nodes $i$ and $j\left(\bar{x}_{i}^{k}\right.$ and $\left.\bar{z}_{i j}^{k}\right)$, $i=1, \ldots, n, \quad j=1, \ldots, n, \quad i \neq j \quad$ for $k$-th hour, $k=1, \ldots, N$.

For estimation of electricity shortage in the considered hours we use the following problem [10]. Generated electricity $x_{i}$ in node $i, \mathrm{kWh}$, consumed electricity $y_{i}$ in node $i, \mathrm{kWh}$, transmitted electricity $z_{i j}$ from node $i$ to node $j, \mathrm{kWh}$, are variables in the problem, $i=1, \ldots, n, j=1, \ldots, n$. The problem of estimation of electricity shortage in $k$-th hour, $k=1, \ldots, N$, is written as

$$
\begin{gathered}
\sum_{i=1}^{n} y_{i} \rightarrow \max \\
x_{i}-y_{i}+\sum_{j=1}^{n}\left(1-\gamma_{j i} z_{j i}\right) z_{j i}-\sum_{j=1}^{n} z_{i j}=0, i=1, \ldots, n, \\
0 \leq y_{i} \leq \tilde{y}_{i}^{k}, i=1, \ldots, n
\end{gathered}
$$




$$
\begin{gathered}
0 \leq x_{i} \leq \bar{x}_{i}^{k}, i=1, \ldots, n, \\
0 \leq z_{i j} \leq \bar{z}_{i j}^{k}, i=1, \ldots, n, j=1, \ldots, n, i \neq j .
\end{gathered}
$$

Here $\gamma_{i j}$ are positive coefficients of electricity losses under power transmission from node $i$ to node $j, i \neq j$. Let the set of $\hat{x}_{i}^{k}, \hat{y}_{i}^{k}, \hat{z}_{i j}^{k}$ is an optimal solution of the problem (6) - (10), $k=1, \ldots, N, \quad i=1, \ldots, n$, $j=1, \ldots, n, i \neq j$. The value of electricity shortage in node $i, i=1, \ldots, n$, is computed by the formula

$$
w_{i}^{k}=\tilde{y}_{i}^{k}-\hat{y}_{i}^{k}, k=1, \ldots, N
$$

If the value

$$
w^{k}=\sum_{i=1}^{n} w_{i}^{k}
$$

is positive for some number $k$ we call the $k$-th hour as the hour with electricity deficit. Let's number all such hours and denote their total amount by $H$. Then the probability of non-shortage work of electric power system is computed by the next formula

$$
P=1-\frac{H}{N}
$$

The mathematical expectation of electricity shortage in the nodes of the electric power system is found by

$$
M w_{i}=\sum_{j=1}^{H} \frac{w_{i}^{j}}{N}, i=1, \ldots, n .
$$

That's the way the mathematical expectation of electricity shortage in electric power systems is calculated by the next rule

$$
M w=\sum_{i=1}^{n} M w_{i}
$$

The mathematical expectation of electricity price is computed in the same way

$$
M P=\frac{1}{N} \sum_{k=1}^{N} p\left(\tilde{y}^{k}\right) .
$$

The mathematical expectation of maximal price in every system node $i, i=1, \ldots, n$, can be found by $M \beta_{i}=\frac{1}{N} \sum_{k=1}^{N} \beta_{i}^{k}$.

Simulation and analysis of $N$ hours for the every scenario of development of the electric power system allow to estimate the value of satisfying demand, $\dot{y}_{i}$, the value of produced electricity $\dot{x}_{i}$ in every node and value of electricity flows $\dot{z}_{i j}$ in the system

$$
\dot{y}_{i}=\frac{1}{N} \sum_{k=1}^{N} \hat{y}_{i}^{k}, \dot{x}_{i}=\frac{1}{N} \sum_{k=1}^{N} \hat{x}_{i}^{k}, \dot{z}_{i j}=\frac{1}{N} \sum_{k=1}^{N} \hat{z}_{i j}^{k} .
$$

$k=1, \ldots, N, i=1, \ldots, n, j=1, \ldots, n, i \neq j$. Using these indexes, we evaluate of the behavior of agents interacting in the electricity market.

\section{The behavior of economic agents}

Let $R$ is some reliability index which characterizes fault rate, their duration, and depth for the every scenario of development of the electric power system. In the general case, we can use $n$-dimensional vector instead of $R$. Components of the vector are meanings of some reliability index obtained for system nodes. We assume that the values of the index $R$ cannot be below a certain level $\underline{R}$ and cannot be above a level $\bar{R}$.

Payment of reliability is an amount of money per $\mathrm{kWh}$ which consumer agrees to pay for reliable and continuous power supply. Electricity price with the reliability payment can be presented in the form of an increasing function $g(R)$. View of function $g(R)$ depends on the choice of the reliability index.

\subsection{Modeling of the electricity price with the reliability payment}

The electricity price with the reliability payment can be defined either for every type of consumer or every system node. For the last case the reliability indexes $R_{i}$, $i=1, \ldots, n$, are computed for every node of the system. We suppose that the electricity price with the reliability payment in the node $i$ is presented as a function

$$
g\left(R_{i}\right)=\left(R_{i}\right)^{m} M P .
$$

Here $M P$ is the mathematical expectation of the price of electricity, $m$ is parameter defining of importance of reliability factor for consumer.

\subsection{Modeling of the generating company behavior}

The generating company with number $s, s=1, \ldots, S$, obtains profit depending of reliability indexes $R_{i}$, $i=1, \ldots, n$,

$$
\pi_{s}\left(\dot{x}_{s}, R\right)=\sum_{i=1}^{n} g\left(R_{i}\right) \dot{x}_{s i}-\sum_{i=1}^{n} C_{s}\left(R_{i}, \dot{x}_{s i}\right)
$$

Here $R$ is $n$-dimensional vector with $R_{i}$ components, $\dot{x}_{s i}$ is the mathematical expectation of generated electricity of $s$-th generating company in node $i, \dot{x}_{s}$ is $n$ dimensional vector with $\dot{x}_{s i}$ components, $C_{s}\left(R_{i}, \dot{x}_{s i}\right)$ is operating and investment costs of generating company $s$ needed for providing a certain level of reliability $R_{i}$ and electricity output $\dot{x}_{s i}$ in a node $i, i=1, \ldots, n, s=1, \ldots, S$.

Generating company $s, s=1, \ldots, S$, solves the problem of maximization of function (12) subject to constraints 


$$
\underline{R}_{i} \leq R_{i}, i=1, \ldots, n
$$

or

$$
R_{i} \leq \bar{R}_{i}, i=1, \ldots, n
$$

depending on a view of the reliability index $R_{i}$.

\subsection{Choice of the best development variant for the electric power system}

Development variant of the electric power system with maximal social welfare is confessed as the best. Therefore, the problem of adequacy optimization is written as

$$
S W=\sum_{s=1}^{S} \pi_{s}\left(\dot{x}_{s}, R\right)+C S(\dot{y}, R) \rightarrow \max .
$$

Here $\dot{y}$ is $n$-dimensional vector with $\dot{y}_{i}$ components, $i=1, \ldots, n, \quad C S(\dot{y}, R)$ is a consumer surplus which depends on the reliability level of electricity supply and satisfying electricity demand in nodes. Consumer surplus is defined as a difference between the utility of electricity using and the mathematical expectation of electricity payments

$$
C S(R)=\sum_{\mathrm{i}=1}^{\mathrm{n}} \int_{0}^{\dot{y}_{i}}\left(M \beta_{i}-\alpha l_{i}\right) d l_{i}-\sum_{\mathrm{i}=1}^{\mathrm{n}} \dot{y}_{i} \cdot g\left(R_{i}\right) .
$$

The problem (15) is solved by enumerative technique.

\section{Experimental Research}

In this section proposed approach is tested on the smallscale scheme of electric power system. It was interesting to compare results of experimental research with monopolistic and oligopolistic price setting. The model of the adequacy optimization under monopoly conditions was earlier described by us in [14]. For experimental research in this article and in the article [14] we used the same parameters in demand and supply functions, identical distribution laws of the random values, which we will present below.

Let's consider the test scheme of electric power system consisting of 5 nodes and 5 links. Table. 1 shows characteristics of generating capacities (generating units with a capacity of $100 \mathrm{MW}$ with an accident rate of 0.045), data of absolute load maximum, information of the system links. In the electric power system, the nodes are connected by a transmission lines with a capacity of $135 \mathrm{MW}$ with an integral accident rate of 0.011 per 100 $\mathrm{km}$ and a loss coefficient of 0.0000001661 .

The given energy system is the system with electricity deficit in spite of excess of summary generation over an absolute maximum of load. The reliability index of system work without electricity shortage is 0.9629 under $N=10000$. The node with number one of this energy system is the node with electricity deficit. The mathematical expectation of electricity shortage is equal to $1.4005 \mathrm{MWh}$ in this node. The total mathematical expectation of electricity shortage is $1.4128 \mathrm{MWh}$.

We suppose to consider the four possible variants of the development of the electric power system

1. The first generating company installs one additional generator with $100 \mathrm{MW}$ capacity in the node №1.

2. Both generating companies extend capacity of the line №1 by 135 MW with building the corresponding transmission line. The costs are divided equally.

3 . Both generating companies install one additional generator with $100 \mathrm{MW}$ capacity in the node №1

4. The first generating company installs one additional generator with $100 \mathrm{MW}$ capacity in node №1 and the second generating company extends the capacity of line №1 by 135 MW with building the corresponding transmission line.

Table 1. Technical characteristics of the investigated EPS

\begin{tabular}{|c|c|c|c|c|c|}
\hline $\begin{array}{c}\text { Node } \\
\text { number, } \\
\text { NoGK }\end{array}$ & $\begin{array}{c}\text { Total } \\
\text { power in } \\
\text { the node, } \\
\text { MW }\end{array}$ & $\begin{array}{c}\text { Absolute } \\
\text { maximum } \\
\text { of load, } \\
\text { MW }\end{array}$ & $\begin{array}{c}\text { Line } \\
\text { num- } \\
\text { ber }\end{array}$ & $\begin{array}{c}\text { Number of } \\
\text { transmission } \\
\text { lines in } \\
\text { communi- } \\
\text { cation }\end{array}$ & $\begin{array}{c}\text { Length, } \\
\text { Km }\end{array}$ \\
\hline $1(1)$ & 500 & 700 & I & 2 & 200 \\
\hline $2(1)$ & 1000 & 700 & II & 2 & 100 \\
\hline $3(2)$ & 1400 & 1300 & III & 1 & 300 \\
\hline $4(1)$ & 1000 & 1000 & IV & 2 & 200 \\
\hline $5(2)$ & 1200 & 1100 & V & 2 & 300 \\
\hline System & 5100 & 4800 & & & \\
\hline
\end{tabular}

The costs on capital for the installation of $1 \mathrm{~kW}$ of generating capacity are $1000 \$$. The costs on capital for the building of $1 \mathrm{~km}$ of the electrical transmission line are $3.6 \$$ per $1 \mathrm{~kW}$ (correspond to $220 \mathrm{~kW}$ electric line). The discount factor is 0.065 (refund within 15 years).

We consider the homogeneous consumers with similar preferences. Therefore, $\beta_{i}$ is equal $\beta_{j}$ and $\alpha_{i}$ is equal $\alpha_{j}$ for all demand functions, $i=1, \ldots, n$, $j=1, \ldots, n, i \neq j$. In our research $\beta$ is equal 8650 and $\alpha$ is equal 0.55 . We use the probability of the system work without electricity shortage $P$ as the reliability index in (11). Reliability index $P$ is computed for every variant of the development of the electric power system. The parameter $m$ defines a type of the consumer, $m \in\{0.2 ; 20\}$.

We have two identical generating companies. The profit for the generating company $s, s \in\{1,2\}$ is computed by

$$
\pi_{s}=g \sum_{i=1}^{n} \tilde{x}_{s i}-0.08\left(\sum_{i=1}^{n} \tilde{x}_{s i}\right)^{2}-50 \sum_{i=1}^{n} \tilde{x}_{s i}-N C .
$$

Here $N C$ are costs of network development which can be computed according to above data. Table 2 shows the results of computations for the variants of the development of the electric power system with $N=$ 10000 . 
If we compare the obtained results of experimental research with results for the monopolistic price setting [14] then we can see that electricity prices with payment for reliability electricity supply below and social welfare above in the oligopoly case than monopoly case. At the same time the best variant of development of the electric power system coincide in both cases.

Table 2. Comparison of cases scenario

\begin{tabular}{|c|c|c|c|c|c|}
\hline Case EPS & $\begin{array}{c}\text { non- } \\
\text { shortage } \\
\text { work } \\
\text { probabi- } \\
\text { lity }\end{array}$ & $M \vec{w}$ & $\sum_{k=1}^{N} \hat{y}_{i}^{k}$ & $\sum_{k=1}^{N} \hat{x}_{i}^{k}$ & $\begin{array}{c}\text { Price, } \\
p\end{array}$ \\
\hline Initial & 0.932 & 5.25 & 3553 & 3555 & 3908 \\
\hline 1 (+power) & 0.976 & 2.01 & 3558 & 3559 & 3918 \\
\hline 2 (+line) & 0.985 & 1.23 & 3564 & 3565 & 3914 \\
\hline 3 (+2power) & 0.999 & 0.02 & 3569 & 3570 & 3928 \\
\hline $\begin{array}{c}4 \text { (+power } \\
\text { +line) }\end{array}$ & 0.999 & 0.005 & 3564 & 3564 & 3924 \\
\hline
\end{tabular}

Table 3. Comparison of cases scenario for $m=0: 2$ for consumers with high adequacy requirements

\begin{tabular}{|l|l|l|c|l|}
\hline Case EPS & $\begin{array}{c}g, \\
\text { RUR/MWh }\end{array}$ & $\begin{array}{c}\text { Profit 1, } \\
\text { RUR }\end{array}$ & $\begin{array}{c}\text { Profit 2, } \\
\text { RUR }\end{array}$ & $\begin{array}{c}\text { Welfare, } \\
\text { RUR }\end{array}$ \\
\hline Initial & 3998 & 4787920 & 1669220 & $\mathbf{8 9 5 9 9 7 0}$ \\
\hline 1 (+power) & 3913 & 3255405 & 2465200 & 6561336 \\
\hline 2 (+line) & 3911 & -23580 & -29780 & 60425 \\
\hline 3 (+2power) & 3915 & 1276813 & 906711 & 271906 \\
\hline $\begin{array}{l}\text { 4 (+power } \\
\text { line) }\end{array}$ & 3917 & 6474587 & 2567859 & 6760577 \\
\hline
\end{tabular}

Table 4. Comparison of cases scenario for $\mathrm{m}=20$ for consumers with high adequacy requirements

\begin{tabular}{|l|l|l|l|l|}
\hline \multicolumn{1}{|c|}{ Case EPS } & $\begin{array}{c}g, \\
\text { RUR/MWh }\end{array}$ & $\begin{array}{c}\text { Profit 1, } \\
\text { RUR }\end{array}$ & $\begin{array}{c}\text { Profit 2, } \\
\text { RUR }\end{array}$ & $\begin{array}{l}\text { Welfare, } \\
\text { RUR }\end{array}$ \\
\hline Initial & 1310 & 1234120 & $\begin{array}{l}2434452 \\
7\end{array}$ & 3725473 \\
\hline 1 (+power) & 3182 & 1556776 & 2613749 & 3819681 \\
\hline 2 (+line) & 3595 & -608931 & -434020 & -1137814 \\
\hline 3 (+2power) & 3915 & 2045322 & 4276813 & 6724135 \\
\hline $\begin{array}{l}\text { 4 (+power } \\
\text { +line) }\end{array}$ & 3917 & 2567859 & 6474587 & $\mathbf{6 7 6 0 5 7 7}$ \\
\hline
\end{tabular}

\section{Conclusion}

We evolve the earlier developed by us approach [15] to adequacy optimization of liberalized electric power systems. Liberalization of electric power systems supposes competition of the different agents of the electricity market. In the article we present a review of existed methods of generation adequacy management in liberalized electric power systems.

Optimization of adequacy is based on adequacy analysis of variants of development of the electric power system. Optimization criterion is a maximum of social welfare. Social welfare consists of profits of generating companies, consumer surplus, costs for development and servicing of electrical grids. For adequacy analysis we multiple estimate the electricity shortage in random hours of the system work. Analysis of the system work in every random hour is realized in two stages. At first we define values of equilibrium electricity demand in every system node and equilibrium price of electricity according to Cournot model. We consider only electricity market in the model. At the next stage we simulate failures of power generating equipment and transmission lines. The electricity shortage in a current hour is estimated on the second stage. After a whole cycle of analysis, we compute reliability indexes and profits of generating companies. Profits of generating companies are depended on the reliability of the electricity supply. The simulations of random values are based on Monte Carlo method.

We apply the model with quadratic losses of electricity for the estimation of electricity shortage in a random hour. The given model guarantees the uniqueness of distribution of electricity shortage by system nodes and validness of reliability indexes.

Results of experimental research call about that electricity prices with payment for reliability electricity supply below and social welfare above in the oligopoly case than monopoly case. At the same time the best variant of development of the electric power system coincide in both cases. It confirms applicability and usefulness of developed optimization approach.

\section{Acknowledgment}

Supported by the Siberian Branch of the Russian Academy of Sciences project №AAAA-A17117030310449-7, grants №019-010-00183 from Russian Foundation for Basic Research.

\section{References}

1. P. Joskow, J. Tirole, Rand J. Economics, 38(1), 6084 (2007)

2. F. Roquers, Utilities Policy, 16, 171-183 (2008)

3. S. Hunt, John Wiley \& Sons, Inc. (2002)

4. S. Stoft, IEEE Press, John Wiley \& Sons (2002)

5. M.C. Caramanis, IEEE Transactions on Power Apparatus and Systems, 101(12), 4640-4648 (1982)

6. S. Oren, VII SEPORE (2000)

7. J.M. Glachant, M. Saguan, EPRG Working Paper №07/11 (2007)

8. K.M. Haikel, The Energy J., 32(4), 117-157 (2011)

9. D.M. Newbery, M. Grubb, Economics of Energy \& Environmental Policy, 4(2), 65-82 (2015)

10. V.I. Zorkaltsev, L.M. Lebedeva, S.M. Perzhabinsky, Num. Analysis and App., 3(3), 231-240 (2010)

11. A.A. Vasin, V.V. Morozov, MAX Press, (2005)

12. N. Aizenberg, 9869 LNCS, 469-479 (2016)

13. H. Moulin, Hermann (1981)

14. N. Aizenberg, S. Perzhabinsky, E3S W. Conf., 25, AN 02004 (2017)

15. N. Aizenberg, S. Perzhabinsky, E3S W. Conf., 58, AN 02020, (2018) 